Research Paper

\title{
Salient Cultural Identities and Consumers' Valuation of Identity Congruent Brands: Consequences for Building and Leveraging Brand Equity
}

Nelson Amaral

Corresponding author: Nelson.Amaral@uoit.ca

University of Ontario Institute of Technology, Canada

Carlos J. Torelli

University of Illinois, Urbana-Champaign, USA

\begin{abstract}
Results from five studies demonstrate that a salient cultural identity can increase consumers' valuation of well-established identity-congruent brands. Compared to a baseline condition, consumers with a salient cultural identity were more likely to promote, to pay a higher price for a branded product, to accept a high stretch extension, and to exhibit stronger self-brand connections in the context of identity-congruent brands. These effects seem to occur rather unconsciously, triggered by fluency when processing a salient identitycongruent brand. They dissipate when consumers' attention is drawn to the source of fluency (i.e., the salient identity). Findings in this research highlight the theoretical importance of understanding the nature of a brand's connections to a consumer's identity for predicting consumer valuation of well-established brands and their leveraging actions.
\end{abstract}

Keywords:Consumer Identity, Cultural Identity, Brand Symbolism, Brand Valuation, Brand Extensions, Brand Management 


\section{Introduction}

As a consumer, John can have multiple identities (as a father, a researcher, a male, an American), some of which he more strongly associates with than others (and hence, are more likely to be chronically salient for him). Additionally, it is also possible that some of these identities become more salient under specific

circumstances (e.g., his identity as a father, when he is playing with his 5 year old daughter). A central question that this research asks is whether his valuation of a brand (e.g., willingness to pay for a Nike product, or openness to trying a relatively high stretch extension such as, Nike Cola) is likely to differ depending upon his salient identities? In other words, would a consumer be likely to value a salient identitycongruent brand (e.g., a brand strongly associated with the identity-related schema) and its products more if and when that identity is salient for him? Past research has discussed how making a consumer's social identity salient can result in higher likelihood of favorably evaluating hypothetical products that are either promoted in identity-relevant terms (e.g., a fictitious apparel brand endorsed by somebody from the same social group, Chattaraman, Lennon, \& Rudd, 2010) or that consensually symbolize the identity (e.g., an ethnic food; Stayman \& Deshpandé, 1989). In addition, consumers have been shown to switch choices between brands to those that are identity-congruent as opposed to incongruent (e.g., rating more favorably an identity-congruent brand shown side-by-side with an incongruent one, Chattaraman, et al., 2010). However, relatively less is known about the effects of salient social identities in the valuation of well-established brands and their leveraging actions, as well as the boundary conditions for the valuation effects. As this research demonstrates, the mechanism as well as outcomes relating to the impact of identity-congruence on brand valuation, is likely to differ in the context of well-established as compared to hypothetical brands (which have been the focus of past research).

Building on past work, this research not only demonstrates that a salient social identity can increase the valuation of identity-congruent brands across different settings and dependent variables, but also argues that this change in valuation occurs unconsciously and can be reversed if the consumer becomes conscious of this process-which would argue against the recommendation to highlight identity-based connections in product messages. Additionally, the research suggests that identity congruence may be a double-edged sword, although it can help a brand (and its products), it also has the potential to hurt; and in this regard, it identifies boundary conditions for the reversal of the brand valuation effect. This research highlights the theoretical importance of understanding the nature of a brand's connections to a consumer's identity for predicting consumer valuation of brands and their leveraging actions.

Specifically, the article proposes an unconscious fluency-based mechanism by which consumers salient identities influence their valuation of brands. The analysis concentrates on cultural identities that are often related to well-developed schemas, and suggest that when such identities are salient, (implying an activated schema related to that identity, e.g., American, Hispanic, or female identity) brands strongly associated with that schema are processed more fluently and hence, enjoy an advantage in terms of enhanced valuation effects (e.g., willingness to pay more for a branded product or increased receptivity to its brand extensions). In 
other words, the research argues that after controlling for the brand's prior liking and equity, fluency-based effects lead to higher valuation of its products by consumers whose salient identity overlaps with a schema that the brand is also associated with. These effects are robust and not only emerge in situations where consumers have chronically salient identities, but also when such identities are made temporarily salient. A series of 4 studies demonstrate the reflexive nature of these effects and outline boundary conditions for them Specifically, this effect can be attenuated when the identity-based connection is explicitly pointed out to consumers, suggesting that it may not be beneficial for brands to explicitly point out these connections in their advertising copy and taglines. Additionally, it is reversed (to a disadvantage) when the branded product has the potential to activate a competing cultural schema (and hence create disfluency).

The rest of this article is organized as follows. It starts by providing the theoretical motivations for the

hypotheses. This is followed by four empirical studies that test these hypotheses. The article finishes with a discussion of the theoretical and marketing implications of the results, as well as with suggestions for future research.

\section{Background Literature And Hypotheses Development}

\section{Brands as Symbols of Consumer Identities}

People buy products not only for what they do, but also for what the product means; thus brands can be symbols that become part of the individual identities of consumers (Levy, 1959). Through the process of social consensus building (Krauss \& Fussell, 1996; McCracken, 1986), some brands acquire cultural meanings and become associated with the abstract characteristics that define a cultural identity (J. L. Aaker, Benet-Martinez, \& Garolera, 2001; Han \& Shavitt, 1994; Torelli \& Cheng, 2011). For instance, hedonic products or automobiles respectively characterize French or Japanese cultures (S.-T. Hong \& Kang, 2006; Leclerc, Schmitt, \& Dubé, 1994) as much as brands like Budweiser or Sony respectively characterize American or Japanese cultures (Torelli \& Ahluwalia, 2012). A brand's cultural symbolism is defined as perceived consensus of the degree to which the brand symbolizes the abstract image of a certain cultural group (Torelli \& Ahluwalia, 2012; Torelli \& Cheng, 2011; Torelli, Keh, \& Chiu, 2010). Because members of a cultural group typically agree on the assumed sharedness of culturally-relevant beliefs (Wan, Torelli, \& Chiu, 2010; Zou, et al., 2009), cultural symbolism is measured via ratings of the extent to which an average group member perceives that a target brand symbolizes the cultural identity (Torelli \& Ahluwalia, 2012; Torelli, et al., 2010; Wan, et al., 2010).

\section{Salience of Identity-based Schemas and Processing of Associated Brands}

Consumer identity-based schemas, including cultural schemas, comprise a loose network of shared beliefs and associations (including brands and products) about a human group (e.g., Chinese), that can operate below consciousness and guide cognition only when they are accessible (Chiu \& Hong, 2006; Reed, 2002). These schemas can be defined at the national level (e.g., American identity) or for sub-groups that co-exist within national boundaries (Torelli, 2013; Torelli, Ahluwalia, Cheng, Olson, \& Stoner, 2017). When some aspect of such a schema becomes salient (either chronically or temporally), the associated elements in the rest of the schema also become activated via the mechanism of spreading activation, increasing the cognitive accessibility of these elements (Y.-Y. Hong, Morris, Chiu, \& Benet- 
Martinez, 2000). Their increased cognitive accessibility facilitates in the identification of these elements (Biederman, 1995), making their processing easier or more fluent (i.e., rendering them conceptually fluent, Shapiro, 1999; Shapiro, Macinnis, \& Heckler, 1997). Processing fluency, or ease with which a target stimuli is processed, is known to enhance stimuli evaluations (e.g., Lee \& Labroo, 2004; Reber, Schwarz, \& Winkielman, 2004; Whittlesea, 1993). Fluency effects are typically driven by the perceiver attributing the higher "ease of processing" experience to higher quality of the target (Avnet \& Higgins, 2003; Camacho, Higgins, \& Luger, 2003).

Therefore, when a consumer identity related schema is salient, it follows that the brands strongly associated with the same cultural schema are likely to be processed fluently by the consumer, generating a feeling of ease, resulting in a pleasing processing experience and an accompanying enhanced evaluation of the brand. The fluency-based processes are known to be relatively automatic in nature (see Schwarz, 1990; also Winkielman, Schwarz, Fazendeiro, \& Reber, 2003, for discussions).

This heightened perception of the brand's value or equity should be evident in consumer's reactions to the marketing efforts of the identity-congruent brand (Keller, 1993), such as, in their increased likelihood to pay higher prices for branded products, to become brand advocates, to favorably evaluate product extensions that deviate from the offerings in the current brand portfolio (i.e., high stretch extensions, Ahluwalia, 2008; Torelli \& Ahluwalia, 2012), and to develop strong connections between the consumer and the brand (i.e., self-brand connections, Escalas \& Bettman, 2003). Stated more formally:

H1: The salience of a cultural identity will increase (compared to a low identity salience condition) the valuation of an identity-congruent brand. This will translate into higher likelihood that consumers will:

(a) become brand advocates

(b) pay higher prices for branded products

(c) accept a brand extension

(d) develop strong self-brand connections

The experiments that follow test the brand valuation effects in these various domains.

\section{Studies 1(A) And 1(B)}

Studies 1(a) and 1(b) were designed to test the basic effect proposed in this research: that is, whether enhancing accessibility/salience of an identity can influence valuation of brands strongly associated with that identity. A sample of American participants from the Twin Cities area in Minnesota was recruited with a view to manipulating the salience of their Minnesotan (a distinctive sub-cultural identity in the American Midwest, Hurt, 2001; Ostergren, 1988). A set of brands were pretested $(\mathrm{n}=18)$ on the strength of their association with the Minnesotan schema.

\section{Method}

One-hundred and fifty-two college students enrolled in the University of Minnesota (United States of America) were recruited to participate in the study in exchange for course credit (45\% male, average age $=20.8$ years). These individuals came from two different samples $\left(\mathrm{N}_{1}=112\right.$ and $\left.\mathrm{N}_{2}=40\right)$ and were all born and raised in the state of Minnesota. They were asked to complete a series of unrelated tasks. The first part of the procedure was similar for participants in both studies. They read an article and listed their thoughts while reading it. Subjects in the "Minnesota salient" condition read an excerpt from a study conducted by a reputable and familiar public policy institute in Minnesota on the trends over time in the decline of Minnesotan identity to activate the associated 
Minnesotan cultural schema (Wicklund \& Gollwitzer, 1981). No brand names or products were associated with or mentioned in this article. In the baseline group, subjects read a neutral story about grasshoppers. Next, all participants completed the Positive and Negative Affect Schedule (PANAS, Watson \& Clark, 1992).

Subsequent to these tasks, participants in both studies were presented with an ostensibly unrelated study being conducted by a known marketing research institute at the university. The nature of the task presented in this part of the experiment was different for Studies 1(a) and 1(b).

In Study 1(a) participants were told about a research study on new types of promotional activities. They were informed that the promotional activity being tested was paying college students to carry a brand logo on their backpacks. Half of the participants in this study were told that the brand involved in the activity was "Target", that emerged from pretests as a brand highly symbolic of Minnesota; $\left.\mathrm{n}=18, M_{\text {Target }}=4.68\right)$. Cultural symbolism was measured via ratings of the extent to which an average group member (i.e., an average Minnesotan) perceives the brand to symbolize the cultural identity (Torelli \& Ahluwalia, 2012; Torelli, et al., 2010; Wan, et al., 2010). The other half of the participants were told that the brand was "Dasani" (relatively lower in association with Minnesota from the same pretests: $M_{\text {Dasani }}=2.28, p<.001$-both brands were equally familiar to participants: $M_{\text {Target }}=5.8$ and $M_{\text {Dasani }}=6.3$ ). Participants were asked to indicate the amount in dollars that they would require as a payment to participate in this promotional activity.

For Study 1(b), in the second part (study ostensibly sponsored by the known marketing research institute), participants were presented with an actual set of poker chips with the "Target" logo stamped on each chip. They were asked to indicate the dollar amount that they would be willing to pay for the set.

In other words, brand valuation was assessed in terms of (i) the amount of remuneration expected by participants to promote the brand in Study 1a, and (ii) the willingness to pay for a new branded product in Study 1b. Thus, in study 1a, increased valuation would imply a smaller dollar amount (H1a); in contrast, in study 1b, increased valuation would imply a larger dollar amount (H1b).

After completing the marketing task, participants, in both studies, answered demographic questions, were debriefed, and dismissed. During debriefing, participants were asked about their suspicion of a possible connection among the tasks they had just completed, and no participant in either study suspected a link between the manipulation task and the marketing task.

\section{Results}

Study1(a). An ANOVA with the brand-identity association (high/Target vs. low/Dasani) and salience of Minnesotan schema (salient vs. baseline) as fixed factors was run on the amount of payment specified by the subjects. The means of the positive $(\alpha=.73)$ and negative $(\alpha=.76)$ affect items were included as covariates in the analysis. A significant brand association $\mathrm{X}$ schema salience interaction, $F(1,106)=5.11, p<.05$, as well as a significant main effect of Minnesotan schema salience, $F(1,106)=5.36, p<.05$, emerged. No other effects were significant $(p>$ .3). As depicted in Fig. 1, simple contrasts indicated that participants were willing to receive less money to carry the "Target" logo on their backpacks in the Minnesotan schema salient (compared to the baseline) condition, $M=10.20$ and 16.13, respectively, $F(1,57)=10.77, p<.005$. In contrast, participants asked for a similar dollar amount for carrying the "Dasani" logo on their backpacks in both the Minnesotan salient vs. baseline conditions, $M=14.67$ and 14.79 , respectively, $p>.9$.

Study1(b). An ANOVA on willingness to pay for the "Target" poker chips with schema salience (salient vs. baseline) as a fixed factor and the mean of the positive and negative affect items ( $\alpha=.74$ and .71 , respectively) as covariates 


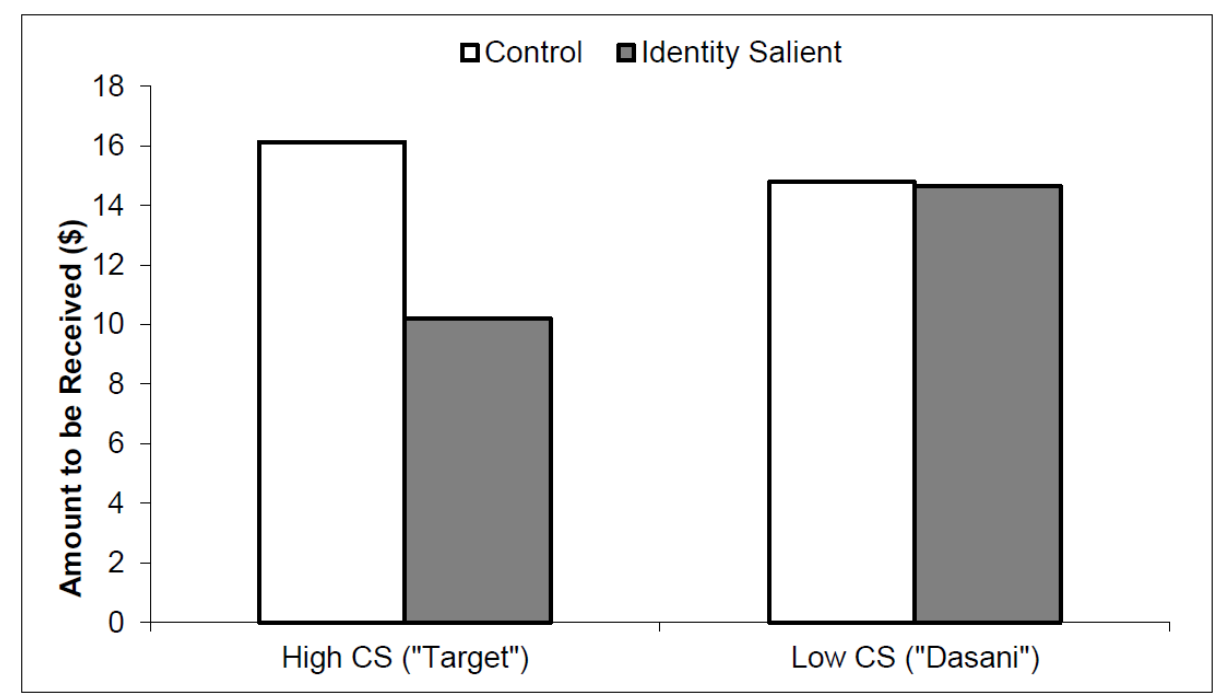

Fig. 1 Amount to Be Received as a Payment as a Function of Cultural Symbolism and Identity Salience - Study 1a

yielded the predicted main effect of identity salience, $F(1,36)=7.77, p<.01$. Participants in the Minnesotan schema salient condition were willing to pay significantly more money for a set of poker chips that carried the "Target" logo as compared to their counterparts in the baseline condition, $M=40.05$ and 25.65 , respectively.

\section{Discussion}

Results from this study suggest that a salient consumer identity is likely to enhance customers' valuation of a brand that is strongly associated with or highly symbolic of that identity. When the Minnesotan identity was made salient, participants were willing to receive less money for promoting a brand high in Minnesota symbolism ("Target"), and also to pay more money for a product that carried the brand's logo, as compared to participants in the baseline condition. No such effect emerged when the brand was low in association with the salient identity ("Dasani"). The overall effects were not driven by differences in mood between the groups, as we controlled for these variables in the analyses, and are better interpreted as driven by a higher valuation of identity symbolic (vs. non-symbolic) brands, when specific consumer identities are salient.

\section{Study 2}

In study 2, participants were prompted to spontaneously elicit their favorite brand and assessed the extent to which they were likely to elicit a brand that was associated with a measured chronic identity schema. The study also assessed the extent to which their level of felt self-brand similarity was influenced by the congruity between their own salient cultural identity and that of the brand. Identity salience was measured instead of manipulated (unlike in studies $1 \mathrm{a} \& 1 \mathrm{~b}$ ), and for a different type of consumer identity (national identity) for two different samples (American and Chinese consumers).

This study used cultural identities defined at the national level (e.g., American or Chinese identity), and it was anticipated that participants who had a salient cultural identity (i.e., those highly identified with their cultural group), 
would: (a) be more likely to spontaneously list a brand that was strongly associated with their salient cultural identity schema (since it is also likely to be highly accessible); and (b) report a higher level of self-brand similarity for brands that are highly associated with their salient cultural identity. No such relationships were expected for participants low in identification with the cultural identity.

\section{Method}

A total of 320 individuals took part on this study. Sixty-eight were American undergraduate students enrolled in business courses in the University of Minnesota in the United States of America ( $55 \%$ male, average age $=21.1$ years) and 252 were Chinese students in Peking University in China (46\% male, average age $=22.2$ years). American participants completed the study in English in exchange for course credit, whereas Chinese participants completed the study in Chinese (survey was translated using standard back translation procedures, Brislin, 1970) and were compensated with 20 Chinese yuan (about \$3) for their participation.

Participants were asked to spontaneously list the name of their favorite brand. They were then asked to rate their favorite brand in terms of cultural symbolism for Americans (Chinese) (scale based on Torelli and Ahluwalia (2012) and to assess their level of self-brand similarity on a 7-point scale with three items (SBC, $1=$ nothing in common/does not remind me of who $\mathrm{I}$ am/is not a part of me, $7=$ a lot in common/reminds me of who $\mathrm{I}$ am/is a part of me, Fournier, 1994; Swaminathan, Page, \& Gürhan-Canli, 2007). After working on some unrelated tasks, American (Chinese) participants completed a scale that assessed their level of identification with America (China) (11 items, Wan, et al., 2007)). Finally, participants answered demographic questions and were debriefed and dismissed.

\section{Results}

To assess the extent to which participants high in a cultural identity were likely to spontaneously list a brand that was associated with this identity, it was estimated a regression equation with the mean brand cultural symbolism score (CS) $(\alpha=.95)$ as dependent variable and the cultural group identification (CGI) $(\alpha=.89)$, a dummy variable for the cultural group $(0=$ Americans, $1=$ Chinese), and the 2 -way interaction as predictors. Results yielded only a significant coefficient for CGI $(\beta=.28, t(317)=2.72, p<.01$. As expected, the cultural symbolism of the spontaneously elicited brand was significantly higher for high cultural identity consumers $(+1$ SD above the mean) as compared to those who were low in cultural identity ( -1 SD below the mean) $(M=4.04$ vs. 3.58).

Next, it was conducted a regression analysis of the mean self-brand similarity scores $(\alpha=.72)$ with brand cultural symbolism, cultural group identification, a dummy variable for the cultural group ( $0=$ Americans, $1=$ Chinese), and all the 2-way and 3-way interactions as predictors. This analysis yielded a significant coefficient for CGI, $\beta$ $=-.65, t(313)=-2.21, p<.05$, and for the CS X CGI interaction, $\beta=1.74, t(313)=2.24, p<.05$. None of the other coefficients reached significance (all $p>.09$ ). Simple slope analyses revealed that the slope of the linear relationship between reported self-brand similarity and cultural symbolism of the brand was positive and significant for participants high in cultural group identification, slopeAmerican $=.34, t(64)=2.52, p<.025$, and slopeChinese $=.21, \mathrm{t}(249)=4.40, p<.001$ (see Fig. 2 . In contrast, the slopes were non-significantly different from zero for participants low in cultural group identification in both cultural groups $(p>.14)$. 


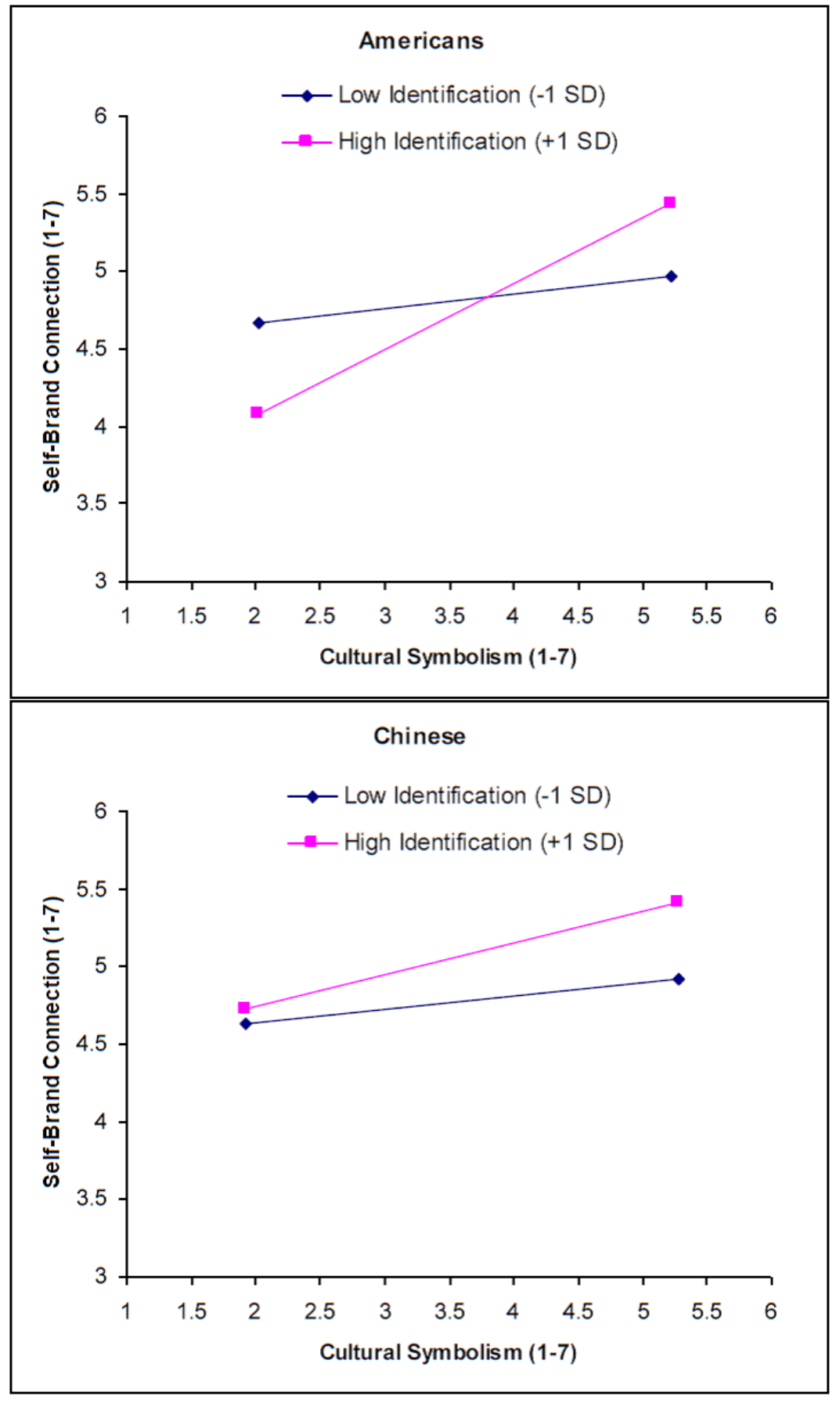

Fig. 2 Self-Brand Connection as a Function of Cultural Symbolism, Cultural Group Identification, and Cultural Group - Study 2

\section{Discussion}

Results from this study show that consumers with a salient cultural identity are not only more likely to spontaneously recall brands that are associated with that identity, but also exhibit stronger levels of self-brand overlap with identityJournal of Management and Training for Industries, Vol.5, No.3, 2018 
congruent brands. Participants high in identification with America (China) (1 SD above the mean) reported stronger bonds with spontaneously recalled brands that symbolized American (Chinese) culture to a greater extent. In contrast, among participants low in group identification (1 SD below the mean), the level of self-brand connection was unrelated to the brand's level of cultural symbolism. These effects emerged with participants from two countries that differ in their levels of individualism and collectivism (Triandis, 1995), which attests to the generalizability of our findings.

It can be argued that the enhancement in studies $1 \mathrm{a} \& 1 \mathrm{~b}$ and the results of study 2 emerge because of fluencybased effects, which are relatively unconscious. However, it is also possible that this enhanced valuation could simply occur because consumers weight the identity-based connection (between brand and their identity) more heavily when that identity is salient (additionally, this connection might also become more apparent in these contexts). In other words, the explanation argued in this research is based on a simple reflexive process, which does not involve conscious deliberation about the brand-consumer identity overlap; however, the alternative explanation implies a more overt and deliberate influence of this connection in consumer decision making. The next two experiments provide some insights on these issues.

\section{Study 3}

This study was conducted to get a better understanding of both the generalizability of this effect as well as the mechanism underlying it. If brands associated with salient identity-related schemas are valued more, then it logically follows that this enhancement effect should also emerge in the domain of brand extensions, since the brand's equity is known to transfer over to the brand extension (Aaker \& Keller, 1990). Thus, brand extensions provide an interesting context to assess the generalizability of the effect reported in the earlier studies.

Importantly, the model in this research proposes a relatively unconscious mechanism, driven by conceptual fluency, as underlying the enhanced valuation effect. Therefore, making the consumers consciously aware of the factor driving their judgments (e.g., enhanced valuations) by providing explicit information about the identity connection (e.g., via an ad tagline), is likely to result in a correction effect, lowering their evaluations of the target (e.g., Fang, Singh, \& Ahluwalia, 2007). In other words, the proposed framework suggests that there may be a potential downside to the inclusion of explicit identity connections in the advertising for these products.

In stark contrast to the implications from this model, if identity congruency effects were driven by a deliberate process (conscious consideration of the identity match), it is expected that inclusion of explicit identity-based connections (e.g., in ad taglines) would result in somewhat stronger or at least similar brand evaluations compared to the baseline (no explicit identity connection) condition for the identity salient consumers (Kardes, 1988; Reed, 2004; Sawyer \& Howard, 1991).

\section{Method}

Thirty-four American consumers who were members of a consumer panel in the Twin Cities of Minneapolis and St. Paul in the United States of America (38\% male, mean age of 21.6 years) were paid $\$ 10$ for participating in a study about new product ideas. On the basis of a first pretest $(\mathrm{n}=39)$, a brand strongly associated with American schema $($ Nike $=5.40$ on 7 -point scales (see Torelli \& Ahluwalia, 2012) was selected for this study. Although Nike is a global brand, American consumers consider it an American icon due to its strong associations with American culture. A hypothetical low fit extension strongly associated with the same American schema $($ Cola $=5.02 ;$ perceived fit $=2.11$, 
on 7-point scales) was chosen as the target product.

In the baseline condition, participants were simply exposed to the concept of Nike cola. In the tagline condition, they were exposed to an ad for this product which contained a tagline explicitly highlighting the American identitybased connection ("An American Icon for Refreshing the American Spirit"). The background image in the ad was a picture of fireworks at the Statue of Liberty. In a pretest $(n=20)$, a similar pool of participants evaluated the tagline favorably $(\mathrm{M}=4.4)$ and perceived it as appropriate for a cola drink $(\mathrm{M}=4.8)$, believable $(\mathrm{M}=4.6)$ as well as realistic $(\mathrm{M}=4.6)$, all significantly above the mid-point of 7-point scales (all p's $<.05)$. A second pretest $(\mathrm{n}=26)$ assessed the thoughts listed in response to the baseline vs. the tagline condition. No specific culture or identity-related thoughts emerged in the baseline condition, demonstrating a lack of conscious elaboration on American identity related schemas in this condition. However, the tagline encouraged elaboration on these types of connections, with subjects reporting significantly more American identity and culture related thoughts $(\mathrm{M}=29.4 \%$ vs. 0\%, Likelihood Ratio Chi-Square $=9.81, \mathrm{p}<.005)$.

After being exposed to the product concept (between subjects design: baseline or tagline), participants evaluated the presented extension (3-items, unfavorable/ favorable, feel cold/feel warm, unappealing/appealing, $\alpha=.91$ ), rated the perceived fit of the extension (3-items, bad fit/good fit, inconsistent/ consistent, dissimilar/ similar, $\alpha=.88$ ), and indicated their intentions to buy it (1-item, would never buy it/for sure would buy it, all 7-point scales). Participants' prior evaluation of the parent brand was assessed in an unrelated task administered before the main study (separated by filler tasks) and used as a covariate in all the analyses. Finally, after some additional filler tasks, participants indicated their level of identification with America (11 items, Wan, et al., 2007), answered demographic questions, and were debriefed and dismissed.

\section{Results}

Perceived fit. Perceived fit was regressed on the information condition ( $0=$ baseline, $1=$ tagline $)$, the mean American identification scores (mean-centered), the 2-way interaction, and attitude towards the parent brand (meancentered). No significant coefficients emerged, all $t<1.1, p\rangle .3$, indicating a lack of any differences by the level of identification with America or between the baseline and tagline conditions on this assessment. This finding indicates that identity-based brand connections are unlikely to be considered by consumers as an input when evaluating an extension's fit with its parent brand.

Extension evaluations and purchase intentions. A similar regression analyses was conducted on the mean extension evaluations and purchase intentions. Results showed that, consistent with predictions in H1c, baseline condition participants high in identification with America not only evaluated the culturally-congruent extension ( 'Nike Cola') more favorably than their low identification counterparts $(M=3.26$ and 1.66 respectively, $t(29)=$ $2.11, p<.05)$, they also indicated a higher intention to buy the new product $(M=2.94$ and .64 respectively, $t(29)$ $=2.83, p<.01)$. Consistent with the model proposed in this research, this identity advantage, however, disappeared in the tagline conditions (Evaluations: $M=1.31$ and 1.55 respectively, n.s.; Buying intentions: $M=1.43$ and 1.21 respectively, n.s.) where the explicit identity-based connection provided participants with a potential source for attributing their experienced fluency. Thus, making the identity overlap explicit led the consumers to discount their subjective experience of fluency, evaluating the extension based on its low level of fit, similar to the low identity participants (Alter \& Oppenheimer, 2009; Torelli, Basu-Monga, \& Kaikati, 2012). 


\section{Discussion}

This study provides support for an unconscious fluency-based mechanism underlying the brand valuation effect. It further demonstrates the robustness of this effect by replicating it in the context of brand extensions, when identity salience was measured as a chronic tendency instead of being manipulated in the lab. Interestingly, the findings reported here suggest that there may not be a clear upside to including explicit identity-congruent information in the advertising for these products (e.g., a tagline that highlights the identity-based connection with the brand); in fact, inclusion of such information could backfire. In other words, our framework indicates that there may be a potential downside to the inclusion of explicit identity-based connections when advertising these brands to consumers for whom this identity is chronically or temporarily salient. Note this relatively novel prediction of the model proposed in this research is grounded in the notion that the brand valuation enhancement, based on the salient identity-congruity effects reported in this research, is driven by an unconscious mechanism.

In light of the findings from the first two studies, demonstrating a robust identity-based brand valuation advantage, a natural question that follows is whether brands that are part of the salient identity schema are always likely to benefit in this manner (if this connection is not explicitly pointed out to them)? Or, can being a consumer identitycongruent brand sometimes become a liability? In other words, what are the boundary conditions for this effect, especially in a brand extension setting? Study 4 examines this issue.

\section{Study 4}

In the evaluation of a brand extension two potential schemas are likely to be accessed - that of the parent brand and the extension product category (e.g., Aaker, 1991; Aaker \& Keller, 1990). Past research demonstrates that when these two components (brand and product) trigger contradicting cultural schemas, then processing disfluency can result (Torelli \& Ahluwalia, 2012). Thus, this research argues that even when the brand is strongly associated with the consumer's salient cultural identity, if the new product (or extension) triggers a different cultural schema, disfluency is likely to result for these consumers, reversing the valuation advantage obtained in the earlier studies. However, consumers for whom the identity schema is not salient are less likely to experience either the fluency or disfluency effects associated with its salience, and hence unlikely to exhibit the enhancement or the reversal. In other words, the model proposed here implies that identity salience overlap may become a disadvantage to brands when the product category itself is strongly associated with an alternate (contradicting) identity schema.

These predictions were tested in study 3, using the context of moderate fit extensions, which are typically evaluated favorably by consumers (Meyers-Levy \& Tybout, 1989).

\section{Method}

A pretest $(\mathrm{n}=47)$ was run to identify brands varying in their strength of association with the American schema. One brand strongly associated with American schema (Budweiser = 5.98), and another neutral in terms of its cultural associations (Coors $=4.32$ ), although identifiable by the participants as an American brand, were chosen for the main study. Notably, these brands received equivalent and high ratings on familiarity (MBudweiser $=5.7$, MCoors $=5.3$, n.s.). In the same pretest, several products (for possible extension categories) were tested for their level of symbolism or association with the American schema as well as other cultural schemas. A moderate fit extension (M 
Table 1 Means and Percentages of Participants Reporting Different Types of Thoughts per Brand and Level of Identification with America - Study 3

\begin{tabular}{|c|c|c|c|c|}
\hline \multirow{3}{*}{ Measures } & \multicolumn{2}{|c|}{ Budweiser } & \multicolumn{2}{|c|}{ Coors } \\
\hline & Low & High & Low & High \\
\hline & Identification & Identification & Identification & Identification \\
\hline Perceived Fit ${ }^{1}$ & $3.29_{a}$ & $2.94_{a}$ & $3.09_{a}$ & $3.06_{a}$ \\
\hline Evaluation $^{1}$ & $2.72_{a}$ & $1.76_{b}$ & $2.73_{a}$ & $3.08_{a}$ \\
\hline Purchase Intention $^{1}$ & $2.64_{a}$ & $1.28_{b}$ & $2.64_{a}$ & $2.81_{a}$ \\
\hline Thoughts - Cultural Schemas ${ }^{2}$ & $11.3_{a}$ & $10.5_{a}$ & $8.9_{a}$ & $9.6_{a}$ \\
\hline Thoughts - Favorable Fit ${ }^{2}$ & $8.6_{a}$ & $9.3_{a}$ & $8.9_{a}$ & $8.5_{a}$ \\
\hline Thoughts - Unfavorable Fit ${ }^{2}$ & $88.6_{a}$ & $81.2_{a}$ & $92.5_{a}$ & $88.1_{a}$ \\
\hline Thoughts - Other ${ }^{2}$ & $55.9_{a}$ & $52.4_{a}$ & $53.6_{a}$ & $51.3_{a}$ \\
\hline
\end{tabular}

NOTES: ${ }^{1}$ Measured on 1-7 scale

${ }^{2}$ Percentage of participants reporting the type of thought

a,b For each brand, cells not sharing the same subscript in the same row differ significantly, $p<.05$

$=3.2$ ) strongly associated with an alternate Mexican schema (Tequila $=5.9$ ) was selected for the main study. For Budweiser tequila, although the Budweiser brand was strongly associated with the American identity, the Tequila product was associated with an alternate Mexican schema. In contrast, since the Coors brand was not strongly associated with either the American or Mexican $(\mathrm{M}=1.67)$ cultural identities, we did not expect any fluency or disfluency effects for it, and was used as a comparison brand.

Sixty-two members of a consumer panel in the Twin Cities of Minneapolis and St. Paul in the United States of America (43\% male, mean age of 21.9 years) were paid $\$ 10$ for participating in a study about new product ideas. After writing down their thoughts about the extension concept, they evaluated the presented extension, rated its perceived fit with the parent brand, and indicated their intentions to buy it (same scales from study 3). Participants' prior evaluation of the parent brand was assessed in an unrelated task administered before the main study (separated by filler tasks) and used as a covariate in all the analyses. Participants' level of identification with America was assessed as in study 3. Finally, they answered demographic questions, and were debriefed and dismissed.

\section{Results}

Fit with Parent Brand. A regression analysis was conducted on the average fit measure $(\alpha=.81)$ with the brand $(0=$ Coors, 1 = Budweiser), the mean American identification scores (mean-centered), the 2-way interaction, and attitude towards the parent brand (mean-centered) as predictors. No significant coefficients emerged, all $t<.5, p>$ .6, indicating a lack of any differences by the level of identification with America or between the brand conditions on this assessment (see Table 1). This finding corroborates that identity-based brand connections are unlikely to be considered by consumers as an input when evaluating an extension's fit with its parent brand.

Extension Evaluations. Similar regression analysis conducted on the mean extension evaluations $(\alpha=.87)$ yielded significant coefficients for the brand $(\beta=-.26, p<.05)$ and the brand $\mathrm{X}$ American identification interaction $(\beta=$ $-.44, p<.025)$. As depicted in Table 1 , and congruent with the reversal that we had predicted, participants high in 
identification with America evaluated Budweiser tequila less favorably than their counterparts low in identification with America did, $M=1.76$ and 2.72 respectively, $t(58)=-2.72, p<.01$, even though the Budweiser brand was strongly associated with their salient American identity. As expected, there were no differences in the evaluation of the neutral Coors tequila extension, by the high vs. low American identification participants $(\mathrm{M}=3.08$ and 2.73 respectively, $n s$ )

Purchase Intentions. A similar analysis on purchase intentions yielded the same pattern of results (Brand: $\beta=$ $-.24, p=.05$; Brand X American identification: $\beta=-.41, p<.025)$. As depicted in Table 1, participants high in identification with America reported a significantly lower intention to purchase the 'Budweiser tequila' than their counterparts low in identification with America did, $M=1.28$ and 2.64 respectively, $t(58)=-3.06, p<.005$. No differences in purchase intentions emerged between the high vs. low identification participants for Coors tequila extension ( $\mathrm{M}=2.81$ and 2.64 respectively, $n s)$.

Thoughts Analyses. Participants' thoughts were coded into four categories: (i) thoughts related to cultural identity-based schemas (any thoughts that related to culture or identity-based schemas, brand's or product's country of origin), (ii) favorable thoughts related to perceived fit of the extension based on brand attributes, product features or other similarities, (iii) unfavorable thoughts related to fit, and (iv) other thoughts (e.g., attitude toward the brand). A comparison of the proportion of individuals reporting the different types of thoughts across conditions, using a simple Pearson chi-square contingency table analyses, suggested that there were no differences in the types of thoughts based on the type of brand or the level of identification with America (Likelihood Ratio Chi-Square $<3.8$, all $p>$ .2 , see Table 1). These findings suggest that the observed effects are unlikely to be driven by conscious elaboration about the cultural identity mismatch between the brand and the product.

\section{Discussion}

The results of this study suggest that the brand valuation effects of identity-congruent brands are unlikely to emerge (and in fact, could be reversed) if the branded product is strongly associated with a different cultural schema. It is important to note that the prior brand evaluation was controlled for (covaried) in this study and the perceived fit did not vary by level of American identification, and hence neither of these factors could explain the pattern of findings obtained.

\section{Conclusions And Future Research}

This research demonstrates that when a cultural identity is salient, consumers process more fluently brands that are strongly associated with such salient identity. As a result, these brands enjoy an advantage in terms of enhanced valuation effects (e.g., willingness to pay more for a branded product or increased receptivity to its brand extensions). Thus, the research shows that after controlling for the brand's prior liking and equity, fluency-based effects lead to higher valuation of its products by consumers whose salient identity overlaps with a schema that the brand is also associated with. These effects are robust and not only emerge in situations where consumers have chronically salient identities, but also when such identities are made temporarily salient.

Results from four studies demonstrate the higher valuation of identity-congruent brands under a salient cultural identity using a variety of methods. Compared to a baseline condition, consumers with a salient cultural identity were more likely to promote (study 1a), to pay a higher price for a branded product (study 1b), to accept a high stretch extension (study 3), and to exhibit stronger self-brand similarity (study 2) in the context of identity-congruent brands. 
These effects seem to occur rather unconsciously and triggered by the fluency when processing an identity-congruent brand upon making salient the corresponding social identity. Attesting to the fluency-based nature of the effect, it dissipated when consumers' attention was drawn to the source of fluency (i.e., the salient identity, study 3). The effects are robust and not only emerge in situations where consumers have chronically salient identities (studies 2,3 and 4), but also when such identities are made temporarily salient (studies 1a and 1b).

Findings in this research also suggest that identity congruence may be a double-edged sword, although it can help a brand (and its products), it also has the potential to hurt. That is the case when a culturally symbolic brand attempts to extend into products that are culturally incongruent (study 4). In this regard, this research identifies boundary conditions for the reversal of the brand valuation effect. Results highlight the theoretical importance of understanding the nature of a brand's connections to a consumer's identity for predicting consumer valuation of well-established brands and their leveraging actions.

Building on past research, which has focused on identity-relevance and identity-congruence in the context of hypothetical products (Chattaraman, et al., 2010; Reed, 2004), this research demonstrates how the salience of a cultural identity is likely to operate in the domain of well-known and well-established brands, in particular those are also likely to be high in cultural/identity symbolism. The research suggests that under these contexts, robust brand valuation effects are likely to emerge via a more unconscious fluency-based route. These findings are very important given recent findings calling into question the role of a brand's cultural association in view of people's inability to recognize the cultural connections of most brands (e.g., Balabanis \& Diamantopoulos, 2008) and/or to articulate culture-related reasons for explaining their brand choices (e.g., Liefeld, 2004). As revealed in this article, the automatic effects of identity congruence are likely to emerge even under the presence of minimal information (i.e., mere presentation of a branded product), and when other pieces of diagnostic information are readily available (e.g., perceived fit) and cultural associations are not very conspicuous (i.e., no inclusion of these associations in ads). Under these settings, processing fluency from identity congruence is likely to boost the valuation of the brand.

One limitation of this research is the reliance on younger consumers in experimental settings for providing the empirical evidence. Although the homogeneity in terms of age, education, and socio-economic status in the samples and the controlled nature of the environments increases the internal validity of the findings, it limits the generalizability across populations (Calder, Phillips, \& Tybout, 1981). However, this limitation is attenuated by the fact that the brands used as stimuli across studies were not only appealing for this younger and more well-off demographic, but also to a broader audience in terms of age, education, and socio-economic status (e.g., Target stores, Dasani bottled water, Nike, and Budweiser). Future research should investigate the effects uncovered here with other consumer groups and using field experiments.

Our research focused on the impact of a salient cultural identity on the valuation of culturally-symbolic brands, but little research has explored how a brand emerges as a cultural icon. Unlike cultural symbols, like flags and commemorative monuments, which are created for the purpose of symbolizing a nation, brands and products originate as commercial offerings. Some of these brands and products, however, gradually attain the status of a cultural icon. Past research has identified some of the factors influencing the extent to which a brand symbolizes a cultural group, such as the embodiment of abstract cultural characteristics (i.e., the embodiment of American values of power, achievement, and success by American icons), or the authenticity for exercising cultural authority (Torelli, 2013; Torelli \& Stoner, 2015). However, future research should investigate the sociological and psychological processes that determine how these factors are incorporated into a unified view of a brand as culturally symbolic.

The current research investigated the role of a salient cultural identity among mono-cultural consumers residing 
in the United States or China. As the number of consumers acquiring knowledge of multiple cultures continues to rise, several important questions surface: How do consumers' acquire and mentally organize knowledge about various cultures? Is consumption behavior influenced by how cultural knowledge is organized in a consumer's memory? Recent research finds that the motivations triggered by cultural primes can be influenced by the organizational structure of cultural frames in memory. Depending on how their cultural identities are organized in memory, bicultural individuals can assimilate or not their behavior to cultural primes (Mok \& Morris, 2013). For instance, AsianAmericans who keep their two cultural identities as separate, incompatible versions of the self (i.e. nonintegrated biculturals) exhibit increased preference for collectivist (individualist) appeals when exposed to Asian (American) primes. For nonintegrated biculturals, cultural primes for one cultural identity are perceived as a threat to their other cultural identity. In an attempt to reaffirm the identity of the un-primed cultural identity in response to this threat, these individuals assimilate their behavior to the un-primed identity. This finding makes apparent the motivational conflict that bicultural individuals can experience when reacting to cultural cues. Future research should assess the extent to which the effects uncovered here extend to samples of bicultural consumers.

The findings here also carry practical implications for marketers by uncovering situations in which explicitly communicating identity-relevant information in advertisements can backfire, or by delineating boundaries for the benefits of identity congruence. When leveraging the equity of well-established culturally symbolic brands into culturally-congruent far extensions, marketers might want to avoid explicitly highlighting the cultural associations, as this can backfire and lower evaluations of the extension product among consumers for whom these identities are salient. This recommendation seems to be at odds with past findings advocating for explicitly highlighting how hypothetical products can help consumers fulfill a salient social identity (Reed, 2004). However, one notable difference between the promotion of a hypothetical product and that of a well-established brand is that the consumer factor in their extant brand knowledge when evaluating a product in the latter situation. Particularly, in the leveraging context of study 3, the fit between the brand attributes and the product features should dominates consumers' conscious thoughts (Aaker \& Keller, 1990), thus relegating cultural associations to the background and facilitating their influence via a fluency-based process. Further investigating the contexts in which pointing to identity-relevant information can be detrimental seems a fruitful area for further research.

Culturally-symbolic brands are unique in the sense that they embody abstract cultural characteristics that can be easily brought to mind upon brand exposure. For marketers, this can be an asset or a liability depending on the context. Because culturally-symbolic brands serve a cultural identity function, consumers can establish strong bonds with these brands when cultural identity needs are temporarily or chronically salient. In addition, abstract cultural images brought to mind by a culturally-symbolic brand can further facilitate successful brand extensions into new products that are also culturally-symbolic when the cultural identity is chronically or temporarily salient. This occurs even if these products fall outside the brand's perceived area of expertise. However, a brand's cultural symbolism can also be a liability and elicit unfavorable consumer reactions. That is the case when introducing products that are culturally incongruent, particularly among consumers who are chronically high in their cultural identification. As a result, culturally-symbolic brands are at a disadvantage when leveraging brand equity through extensions into culturally-incongruent products, even when these products fall within the brand's perceived area of expertise.

In summary, the present manuscript offers a framework to better understand how salient social identities can impact the valuation of well-established identity-congruent brands. The discussions here illustrate the theoretical and practical significance of studying the interplay between the salience of consumers' social identities and the corresponding social identity meanings of brands for understanding the sources of a brand's equity. 


\section{References}

Aaker, D. A. (1991). Managing Brand Equity. New York: The Free Press.

Aaker, D. A. \& Keller, K. L., 1990. Consumer Evaluations of Brand Extensions. Journal of Marketing, 54, 27-41.

Aaker, J. L., Benet-Martinez, V. \& Garolera, J., 2001. Consumption Symbols as Carriers of Culture: A Study of Japanese and Spanish Brand Personality Constucts. Journal of Personality and Social Psychology, 81, $492-508$.

Ahluwalia, R., 2008. How Far Can a Brand Stretch? Understanding the Role of Self-Construal. Journal of Marketing Research, 45, 337-350.

Alter, A. L. \& Oppenheimer, D. M., 2009. Uniting the Tribes of Fluency to Form a Metacognitive Nation. Personality and Social Psychology Review, 13, 219-235.

Avnet, T. \& Higgins, T. E., 2003. Locomotion, Assessment, and Regulatory Fit: Value Transfer from "How" to "What". Journal of Experimental Social Psychology, 39, 525-530.

Balabanis, G. \& Diamantopoulos, A., 2008. Brand Origin Identification by Consumers: A Classification Perspective. Journal of International Marketing, 16, 39-71.

Biederman, I., 1995. Visual Object Recognition. In S. M. Kosslyn \& D. N. Osherson (Eds.), Visual Cognition: An Invitation to Cognitive Science (pp. 121-166). Cambridge, MA: The MIT Press.

Brislin, R. W., 1970. Back-Translation for Cross-Cultural Research. Journal of Cross-Cultural Psychology, 1, 185216.

Calder, B. J., Phillips, L. W. \& Tybout, A. M., 1981. Designing Research for Application. Journal of Consumer Research, 8, 197-207.

Camacho, C. J., Higgins, T. E. \& Luger, L., 2003. Moral Value Transfer from Regulatory Fit: What Feels Right is Right and What Feels Wrong is Wrong. Journal of Personality and Social Psychology, 84, 498-510.

Chattaraman, V., Lennon, S. J. \& Rudd, N. A., 2010. Social Identity Salience: Effects on Identity-based Brand Choices of Hispanic Consumers. Psychology 83 Marketing, 27, 263-284.

Chiu, C. Y. \& Hong, Y. Y., 2006. Social Psychology of Culture. New York: Psychology Press.

Escalas, J. E. \& Bettman, J. R., 2003. ou Are What They Eat: The Influence of Reference Groups on Consumers' Connections to Brands. Journal of Consumer Psychology, 13, 339-348.

Fang, X., Singh, S. \& Ahluwalia, R., 2007. An Examination of Different Explanations for the Mere Exposure Effect. Journal of Consumer Research, 34, 97-103.

Fournier, S., 1994. A Consumer-Brand Relationship Framework for Strategic Brand Management. unpublished dissertation, Graduate School, University of Florida, Gainsville, FL 32611.

Han, S.-p. \& Shavitt, S., 1994. Persuasion and Culture: Advertising Appeals in Individualistic and Collectivistic Societies. Journal of Experimental Social Psychology, 30, 326-350.

Hong, S.-T. \& Kang, D. K., 2006. Country-of-Origin Influences on Product Evaluations: The Impact of Animosity and Perceptions of Industriousness Brutality on Judgments of Typical and Atypical Products. Journal of Consumer Psychology, 16, 232-239.

Hong, Y.-Y., Morris, M. W., Chiu, C.-Y. \& Benet-Martinez, V., 2000. Multicultural Minds: A Dynamic Constructivist Approach to Culture and Cognition. American Psychologist, 55, 709-720.

Hurt, D., 2001. Midwestern Distinctiveness. In A. R. L. Cayton \& S. E. Gray (Eds.), The American Midwest: Essays on Regional History. Bloomington: Indiana University Press.

Journal of Management and Training for Industries, Vol.5, No.3, 2018 
Kardes, F. R., 1988. Spontaneous Inference Processes in Advertising: The Effects of Conclusion Omission and Involvement on Persuasion. Journal of Consumer Research, 15, 225-233.

Keller, K. L., 1993. Conceptualizing, Measuring, Managing Customer-Based Brand Equity. Journal of Marketing, $5 \%, 1-22$.

Krauss, R. M. \& Fussell, S. R., 1996. Social Psychological Models of Interpersonal Communication. In E. T. Higgins \& A. W. Kruglanski (Eds.), Social Psychology: Handbook of Basic Principles (pp. 655-701). NY: Guilford Press.

Leclerc, F., Schmitt, B. H. \& Dubé, L., 1994. Foreign Branding and Its Effects on Product Perceptions and Attitudes. Journal of Marketing Research, 31, 263-270.

Lee, A. Y. \& Labroo, A. A., 2004. The Effect of Conceptual and Perceptual Fluency on Brand Evaluation. Journal of Marketing Research, 41, 151-165.

Levy, S. J., 1959. Symbols for Sale. Harvard Business Review, 37, 117-124.

Liefeld, J. P., 2004. Consumer Knowledge and Use of Country-of-origin Information at the Point of Purchase. Journal of Consumer Behaviour, 4, 85-96.

McCracken, G., 1986. Culture and Consumption: A Theoretical Account of the Structure and Movement of the Cultural Meaning of Consumer Goods. Journal of Consumer Research, 13, 71-84.

Meyers-Levy, J. \& Tybout, A. M., 1989. Schema Congruity as a Basis for Product Evaluation. Journal of Consumer Research, 16, 39-54.

Mok, A. \& Morris, M. W., 2013. Bicultural Self-defense in Consumer Contexts: Self-protection Motives are the Basis for Contrast versus Assimilation to Cultural Cues. Journal of Consumer Psychology, 23, 175-188.

Ostergren, R. C., 1988. A Community Transplanted. Madison: University of Wisconsin Press.

Reber, R., Schwarz, N. \& Winkielman, P., 2004. Processing Fluency and Aesthetic Pleasure: Is Beauty in the Perceiver's Processing Experience? Personality and Social Psychology Review, 8, 364-382.

Reed, A., 2002. Social Identity as a Useful Perspective for Self-Concept-based Consumer Research. Psychology 64 Marketing, 19, 235-266.

Reed, A., 2004. Activating the Self-Importance of Consumer Selves: Exploring Identity Salience Effects on Judgments. Journal of Consumer Research, 31, 286-295.

Sawyer, A. G. \& Howard, D. J., 1991. Effects of Omitting Conclusions in Advertisements to Involved and Uninvolved Audiences. Journal of Marketing Research, 28, 467-474.

Schwarz, N., 1990. Feelings as Information: Informational and Motivational Functions of Affective States. In Handbook of Motivation and Cognition: Foundations of Social Behavior (Vol. 2, pp. 527-561). New York: Guilford Press.

Shapiro, S., 1999. When an Ad's Influence Is beyond Our Conscious Control: Perceptual and Conceptual Fluency Effects Caused by Incidental Ad Exposure. Journal of Consumer Research, 26, 16-36.

Shapiro, S., Macinnis, D. J. \& Heckler, S. E., 1997. The Effects of Incidental Ad Exposure on the Formation of Consideration Sets. Journal of Consumer Research, 24, 94-104.

Stayman, D. M. \& Deshpandé, R., 1989. Situational Ethnicity and Consumer Behavior. Journal of Consumer Research, 16, 361-371.

Swaminathan, V., Page, K. L. \& Gürhan-Canli, Z., 2007. 'My" Brand or "Our" Brand: The Effects of Brand Relationship Dimensions and Self-Construal on Brand Evaluations. Journal of Consumer Research, 34, 248-259.

Torelli, C. J., 2013. Globalization, Culture, and Branding: How to Leverage Cultural Equity for Building Iconic Brands in the Era of Globalization. New York, NY: Palgrave Macmillan. 
Torelli, C. J. \& Ahluwalia, R., 2012. Extending Culturally Symbolic Brands: A Blessing or a Curse? Journal of Consumer Research, 38, 933-947.

Torelli, C. J., Ahluwalia, R., Cheng, S. Y., Olson, N. J. \& Stoner, J. L., 2017. Redefining Home: How Cultural Distinctiveness Affects the Malleability of In-group Boundaries and Brand Preferences. Journal of Consumer Research, 44, 44-61.

Torelli, C. J., Basu-Monga, A. \& Kaikati, A. M., 2012. Doing Poorly by Doing Good: Corporate Social Responsibility and Brand Concepts. Journal of Consumer Research, 38, 948-963.

Torelli, C. J. \& Cheng, S. Y.-y., 2011. Cultural Meanings of Brands and Consumption: A Window into the Cultural Psychology of Globalization. Social and Personality Psychology Compass, 5, 251-262.

Torelli, C. J., Keh, H. T. \& Chiu, C.-Y., 2010. Cultural Symbolism of Brands. In B. Loken, R. Ahluwalia \& M. J. Houston (Eds.), Brands and brand management: Contemporary Research Perspectives (pp. 113-132). New York: Routledge.

Torelli, C. J. \& Stoner, J. L., 2015. Managing Cultural Equity: A Theoretical Framework for Building Iconic Brands in Globalized Markets. Review of Marketing Research (Brand Meaning Management), 12, 83-120.

Triandis, H. C., 1995. Individualism \& Collectivism. CO: Westview Press.

Wan, C., Chiu, C.-y., Tam, K.-p., Lee, S.-l., Lau, I. Y.-m. \& Peng, S., 2007. Perceived Cultural Importance and Actual Self-importance of Values in Cultural Identification. Journal of Personality and Social Psychology, 92, 337-354.

Wan, C., Torelli, C. J. \& Chiu, C.-Y., 2010. Intersubjective Consensus and the Maintenance of Normative Shared Reality. Social Cognition, 28, 422-446.

Watson, D. \& Clark, L. A., 1992. Affects Separable and Inseparable: On the Hierarchical Arrangement of the Negative Affects. Journal of Personality and Social Psychology, 62, 489-505.

Whittlesea, B. W., 1993. Illusions of Familiarity. Journal of Experimental Psychology: Learning, Memory, and Cognition, 19, 1235-1253.

Wicklund, R. A. \& Gollwitzer, P. M., 1981. Symbolic Self-completion, Attempted Influence, and Self-deprecation. Basic and Applied Social Psychology, 2, 89-114.

Winkielman, P., Schwarz, N., Fazendeiro, T. A. \& Reber, R., 2003. The Hedonic Marking of Processing fluency: Implications for Evaluative Judgment. In J. Musch \& K. C. Klauer (Eds.), The Psychology of Evaluation: Affective Processes in Cognition and Emotion (pp. 189-217). NJ, US: Lawrence Erlbaum Associates Publishers.

Zou, X., Tam, K.-P., Morris, M. W., Lee, S.-l., Lau, I. Y.-M. \& Chiu, C.-Y., 2009. Culture as Common Sense: Perceived Consensus versus Personal Beliefs as Mechanisms of Cultural Influence. Journal of Personality and Social Psychology, 97, 579-597. 